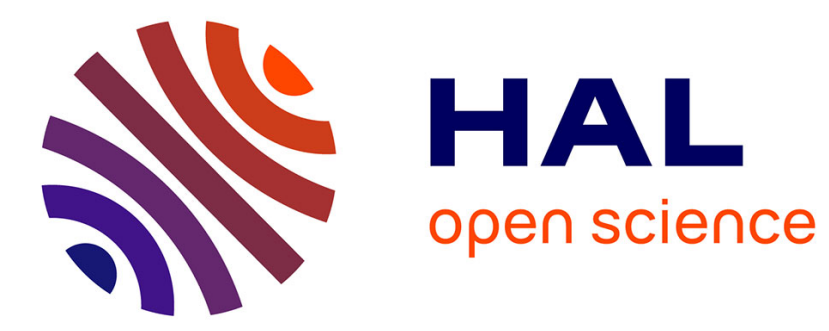

\title{
Impact of Spark Plasma Sintering Conditions on Ionic Conductivity in La1.95Sr0.05Zr2O7- $\delta$ Electrolyte Material for Intermediate Temperature SOFCs
}

Da Huo, Gianguido Baldinozzi, David Siméone, Hicham Khodja, Suzy Surble

\section{- To cite this version:}

Da Huo, Gianguido Baldinozzi, David Siméone, Hicham Khodja, Suzy Surble. Impact of Spark Plasma Sintering Conditions on Ionic Conductivity in La1.95Sr0.05Zr2O7- $\delta$ Electrolyte Material for Intermediate Temperature SOFCs. ECS Meeting Abstracts, 2015, MA2015-03 (1), pp.405. hal01187799

\author{
HAL Id: hal-01187799 \\ https://hal.science/hal-01187799
}

Submitted on 1 Dec 2015

HAL is a multi-disciplinary open access archive for the deposit and dissemination of scientific research documents, whether they are published or not. The documents may come from teaching and research institutions in France or abroad, or from public or private research centers.
L'archive ouverte pluridisciplinaire HAL, est destinée au dépôt et à la diffusion de documents scientifiques de niveau recherche, publiés ou non, émanant des établissements d'enseignement et de recherche français ou étrangers, des laboratoires publics ou privés. 


\title{
Impact of Spark Plasma Sintering Conditions on Ionic Conductivity in $\mathrm{La}_{1.95} \mathrm{Sr}_{0.05} \mathrm{Zr}_{2} \mathrm{O}_{7-\delta}$ Electrolyte Material for Intermediate Temperature SOFCs
}

\author{
D. Huo ${ }^{\mathrm{a}, \mathrm{b}}$, G. Baldinozzi ${ }^{\mathrm{b}}$, D. Siméone ${ }^{\mathrm{b}}$, H. Khodja ${ }^{\mathrm{a}}$, and S. Surblé ${ }^{\mathrm{a}}$ \\ ${ }^{a}$ CEA/DSM/IRAMIS/NIMBE/LEEL, F-91191 Gif-sur-Yvette, France \\ CNRS/UMR 3685/NIMBE/LEEL, F-91191 Gif-sur-Yvette, France \\ b SPMS, LRC CARMEN, Université Paris Saclay, Centrale-Supélec, CNRS, F-92295, \\ Châtenay-Malabry, France \\ CEA/DEN/DANS/DMN/SRMA/LA2M-LRC CARMEN, F-91191, Gif-sur-Yvette, \\ France
}

\begin{abstract}
To overcome the ageing issues of the solid oxide fuel cells (SOFCs), the proton ceramic fuel cells (PCFCs, also called intermediate temperature SOFCs) were developed, which operate at intermediate temperatures $\left(400^{\circ}-600^{\circ} \mathrm{C}\right)$. In this paper, we present the synthesis of Sr-doped lanthanum zirconate pyrochlores $\mathrm{La}_{1.95} \mathrm{Sr}_{0.05} \mathrm{Zr}_{2} \mathrm{O}_{7-\delta}$ (LSZO) that can be used as electrolyte materials. Conductivity measurements of LSZO were performed in dry and wet $\left(\begin{array}{lll}5 \% & \mathrm{H}_{2} \mathrm{O}\end{array}\right)$ atmospheres using electrochemical impedance spectroscopy. As the sintering processes have the potential to affect not only the bulk conductivity but also the response of grain boundaries, five samples prepared under various SPS conditions were studied.
\end{abstract}

\section{Introduction}

Solid Oxide Fuel Cells (SOFCs) have attracted much attention as potential high efficiency and low carbon emission technology. Their high operating temperatures $\left(800^{\circ} \mathrm{C}-1000^{\circ} \mathrm{C}\right)$ can lead to thermal, mechanical and chemical problems such as densification of electrodes or formation of an insulating layer at the electrode/electrolyte interface by interdiffusion $(1,2)$. To overcome these drawbacks, the Proton Ceramic Fuel Cell (PCFC, also called intermediate temperature SOFCs) technology was developed. This technology, where the electrolyte is an $\mathrm{H}^{+}$ion conductor in the form of ceramic oxide material, exhibits the intrinsic benefits of proton conduction in Polymer Exchange Membrane Fuel Cells (PEMFCs) and the advantages of the SOFC technologies.

Since the discovery of high temperature protonic conductivity in cerates $(3,4)$, many other oxide ion conductors have been found to be potential candidates for intermediate temperature SOFC (5-8). Many investigations about pyrochlore-type proton conductors were performed $(9,10)$. These systems often contain mixed-valence in cations (often rare earth) and anion vacancies as primary lattice defects. In order to increase the quantity of vacancy, the substitution of trivalent cations by divalent ones was used.

Many factors impact on the ionic conductivity. Among them, the influence of different synthesis methods on ionic conductivity has been investigated by Kim et al. for aliovalent-doped ceria (11). Marrero-López et al. (12) also reported an effect of 
microstructure on the transport properties of apatite-type electrolyte. Other more specific impacts could be attributed to the grain size and the inter-particle neck size (13) or the pore structure (14). Moreover, high resistivity in the grain boundaries is observed for many ionic conductors and is commonly attributed to blocking impurity phases at the grain boundaries $(15,16)$. Different sample preparation processes may cause all of these factors leading to an increase in resistivity.

The conventional route for the preparation of lanthanum zirconate pyrochlore (LSZO) via solid-state reactions requires multiple milling and high temperature calcination steps. Also, this method leads generally to a heterogeneity of the final product, whereas wet chemical route, which consists of mixing precursors in a solution, could improve compositional homogeneity and stoichiometry. In this work, we have synthesized nanosized $\mathrm{La}_{1,95} \mathrm{Sr}_{0,05} \mathrm{Zr}_{2} \mathrm{O}_{7-\delta}$ using an oxalic co-precipitation method. As impedance spectroscopy measurements require high densification, only spark plasma sintering (SPS) is chosen. Other sintering processes such as hot isostatic pressing induce a segregation of strontium at the surface of the pellet (17), and thereby decrease proton conductivities. We present in this paper the conductivity measurements of different LSZO SPS pellets in dry and wet $\left(5 \% \mathrm{H}_{2} \mathrm{O}\right)$ atmospheres using electrochemical impedance spectroscopy.

\section{Experimental}

Powders of $\mathrm{La}_{1.95} \mathrm{Sr}_{0.05} \mathrm{Zr}_{2} \mathrm{O}_{7-\delta}$ (LSZO) were prepared by a wet chemical method based on a co-precipitation route. $\mathrm{La}\left(\mathrm{NO}_{3}\right)_{3} \cdot 6 \mathrm{H}_{2} \mathrm{O}$ (99.999\%, Aldrich), $\mathrm{Sr}\left(\mathrm{NO}_{3}\right)_{2}$ (99\%, Aldrich) $\mathrm{ZrOCl}_{2} .8 \mathrm{H}_{2} \mathrm{O}(99.5 \%$, Aldrich) and deionized water were first mixed at room temperature in the following ratio: $0.95: 0.05: 1: 833$. Aqueous ammonia (28\%, Aldrich) was slowly added to the nitrate solution in order to adjust $\mathrm{pH}$ at approximately $\mathrm{pH} 4$. Then oxalic acid (Normapur, Prolabo) was used as chelating agent. Metal cations and oxalic acid in a 1:4 ratio were mixed in a minimum of deionized water until a transparent solution was obtained. Gel-like precipitates were instantaneously obtained. The solution including the precipitate was thus dehydrated using a heating plate at low temperature $\left(\mathrm{T}<100^{\circ} \mathrm{C}\right)$. The powders were then ground in an agate mortar and calcined at different temperatures. Different particle sizes were thus obtained.

X-rays diffraction analysis was performed to investigate the crystalline structure of these ceramics, using a Bruker D8 Advance diffractometer with $\mathrm{CuK} \alpha$ radiation. Rietveld refinements were carried out using the XND program (18) to obtain the structural data, the crystallite size and the microstrain.

LSZO powders were densified using SPS apparatus under different sintering conditions: holding time, temperature and pressure. To maintain the same compacity for different grain sizes, starting powders were firstly calcined at different temperatures in order to increase the particle size. Thus several pellets with either different relative densities or grain sizes were obtained.

The proton conductivity behavior of those pellets was investigated by AC impedance spectroscopy under dry and wet $\left(5 \% \mathrm{H}_{2} \mathrm{O}\right)$ atmospheres. Two symmetrical porous $\mathrm{Ag}$ electrodes were deposited by applying a silver paste onto both sides of the dense pellets. Before recording the data, the electrode / electrolyte samples were treated at $400^{\circ} \mathrm{C}$ for $4 \mathrm{~h}$ in air. The data were measured in the $0.1 \mathrm{~Hz}-6 \mathrm{MHz}$ frequency range (Materials mates 
M2-7260 impedance analyzer) at intermediate temperatures $400-600^{\circ} \mathrm{C}$. In order to verify the dependence of total resistance and capacitance, a DC-bias ( $\mathrm{U}_{\mathrm{DC}}$ from 0 to $1 \mathrm{~V}$ ) was applied. The Nyquist diagrams were modeled by equivalent circuits based on resistors and constant phase elements (CPEs).

\section{Results and discussion}

\section{$\underline{\text { Structural Characterizations }}$}

Figure 1 shows the XRD patterns of LSZO calcined at different temperatures. A single phase was observed. All the samples crystallized in the cubic structure. Previous work (17) shows that the $800^{\circ} \mathrm{C}$ calcined material crystallized in the C-type fluorite structure, while the $1500^{\circ} \mathrm{C}$ solid crystallized in the pyrochlore structure. The structures of the intermediate temperature $\left(900^{\circ} \mathrm{C}-1400^{\circ} \mathrm{C}\right)$ calcined powders were refined using both C-type fluorite and pyrochlore structures.

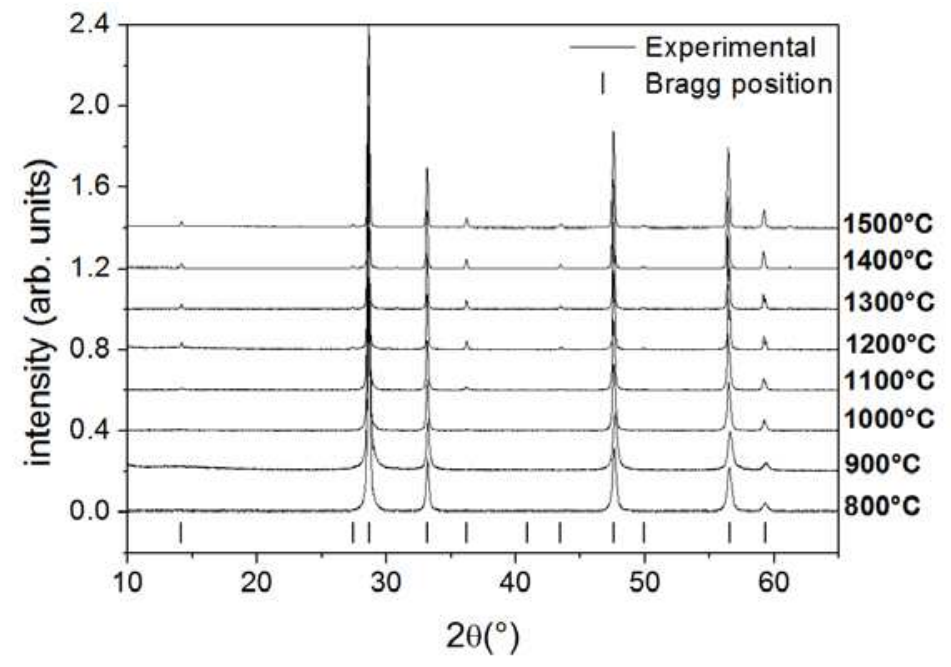

Figure 1. XRD patterns of the LSZO powders calcined at different temperatures.

Attempts to synthetize lanthanum zirconate $\mathrm{La}_{2-\mathrm{x}} \mathrm{Sr}_{\mathrm{x}} \mathrm{Zr}_{2} \mathrm{O}_{7-\delta}$ with higher strontium concentrations were carried out without obtaining single-phase materials. The solid solubility limit of strontium into the lanthanum zirconate pyrochlore structure was $x=0.05$. Beyond this content, secondary phases such as $\mathrm{La}_{2} \mathrm{O}_{3}$ and / or $\mathrm{SrZrO}_{3}$ were observed. An enhancement of the ionic conductivity is observed when the amount of dopant increases. Results presented hereafter were obtained with $\mathrm{x}=0.05$.

The ionic radius of $\mathrm{La}^{3+}$ for coordination 8 is $1.16 \AA$ while that the $\mathrm{Sr}^{2+}$ is higher for the same coordination $(1.26 \AA)$. The radius of $\mathrm{Zr}^{4+}$ showing octahedral environment is $0.72 \AA$ (19). The replacement of $\mathrm{La}^{3+}$ cations by $\mathrm{Sr}^{2+}$ cations increases the lattice parameter, hence shifting the peak position toward smaller angles in XRD patterns. We have applied Vegard's rule to verify the composition of the solid solution in LSZO pyrochlore structure from its lattice parameters (20). Assuming a linear variation in lattice parameter with relative ionic radius, the lattice parameters of LSZO systems were fit into a straight line (Figure 2). The substitution of $\mathrm{La}^{3+}$ ions by $\mathrm{Sr}^{2+}$ at $1500^{\circ} \mathrm{C}$ is confirmed by the lattice parameter (21). 


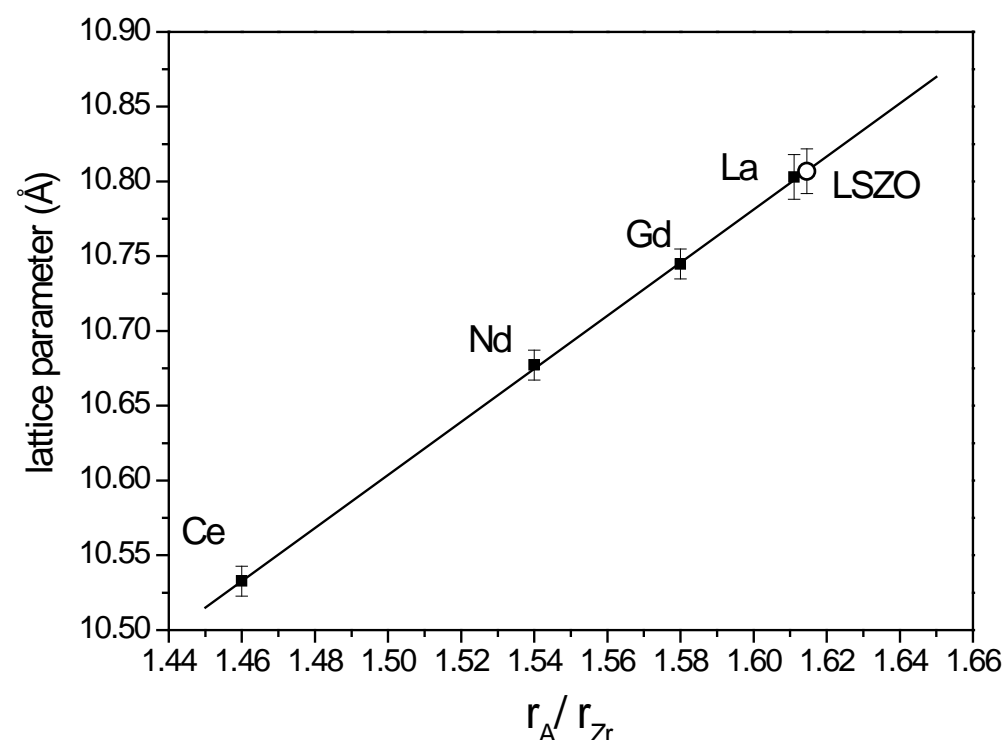

Figure 2. Plot illustrating the composition of pyrochlore materials using Vegard's rule (square: experimental lattice parameter of $\mathrm{A}_{2} \mathrm{Zr}_{2} \mathrm{O}_{7}$ and circle: our work).

\section{Densification Processes}

It is well known that electrochemical properties are influenced by the morphology and the particle size of the sample. As described in our previous work on sintering conditions (17), dense materials can be obtained only by SPS method. A series of LSZO samples were sintered under different temperatures to study the influence of the particle size on electrical properties. Table I lists the conditions used for the densification of LSZO pellets. For the low temperature sintering $\left(1200^{\circ} \mathrm{C}\right)$, two attempts were investigated. For the $1200 \mathrm{P}$ one, as soon as the temperature was reached the pressure increased from 50 $\mathrm{MPa}$ to $100 \mathrm{MPa}$ (in 2 minutes). For the other one (1200T), a pressure of $100 \mathrm{MPa}$ was applied around $400^{\circ} \mathrm{C}$ and maintained while the temperature was progressively increased until $1200^{\circ} \mathrm{C}$. After the same holding time, the pressure and the temperature were released. But this temperature was not enough to have a full densification of the LSZO materials. In order to have full compacity pellets with different grain sizes, several starting powders were used (from $800^{\circ} \mathrm{C}$ to $1500^{\circ} \mathrm{C}$ ). The same process was employed for those sintering. The temperature was progressively increased $\left(100^{\circ} \mathrm{C} /\right.$ minute $)$. Around $600^{\circ} \mathrm{C}$, a $100 \mathrm{MPa}$ pressure was applied until a complete densification of the material. The pressure and the temperature were maintained during 9 minutes, and then released. As shown in Figure 3, the temperature of the full densification was strongly dependent on the initial particle size. The larger is the particle size, the higher temperature of the full densification is observed.

TABLE I. SPS conditions.

\begin{tabular}{cccccc}
\hline $\begin{array}{c}\text { Sample } \\
\text { identification with } \\
\text { the sintering } \\
\text { temperature }\left({ }^{\circ} \mathbf{C}\right)\end{array}$ & $\begin{array}{c}\text { Starting powder } \\
\text { (temperature) }\end{array}$ & $\begin{array}{c}\text { Initial } \\
\text { particle } \\
\text { size }(\mathbf{n m})\end{array}$ & $\begin{array}{c}\text { Time at } \\
\mathbf{1 0 0 M P a} \\
(\mathbf{m i n} .)\end{array}$ & $\begin{array}{c}\text { Compacity } \\
(\boldsymbol{\%})\end{array}$ & $\begin{array}{c}\text { Particle } \\
\text { size } \\
(\mathbf{n m})\end{array}$ \\
\hline LSZO-1200P & $\mathrm{LSZO} 800^{\circ} \mathrm{C}$ & 55 & 36 & 73 & 81 \\
$\mathrm{LSZO}-1200 \mathrm{~T}$ & $\mathrm{LSZO} 800^{\circ} \mathrm{C}$ & 55 & 30 & 80 & 83 \\
$\mathrm{LSZO}-1500$ & $\mathrm{LSZO} 800^{\circ} \mathrm{C}$ & 55 & 9 & 96 & 105 \\
$\mathrm{LSZO}-1600$ & $\mathrm{LSZO} 1300^{\circ} \mathrm{C}$ & 100 & 10 & 96 & 150 \\
$\mathrm{LSZO}-1700$ & $\mathrm{LSZO} 1500^{\circ} \mathrm{C}$ & 108 & 11 & 96 & 165 \\
\hline
\end{tabular}




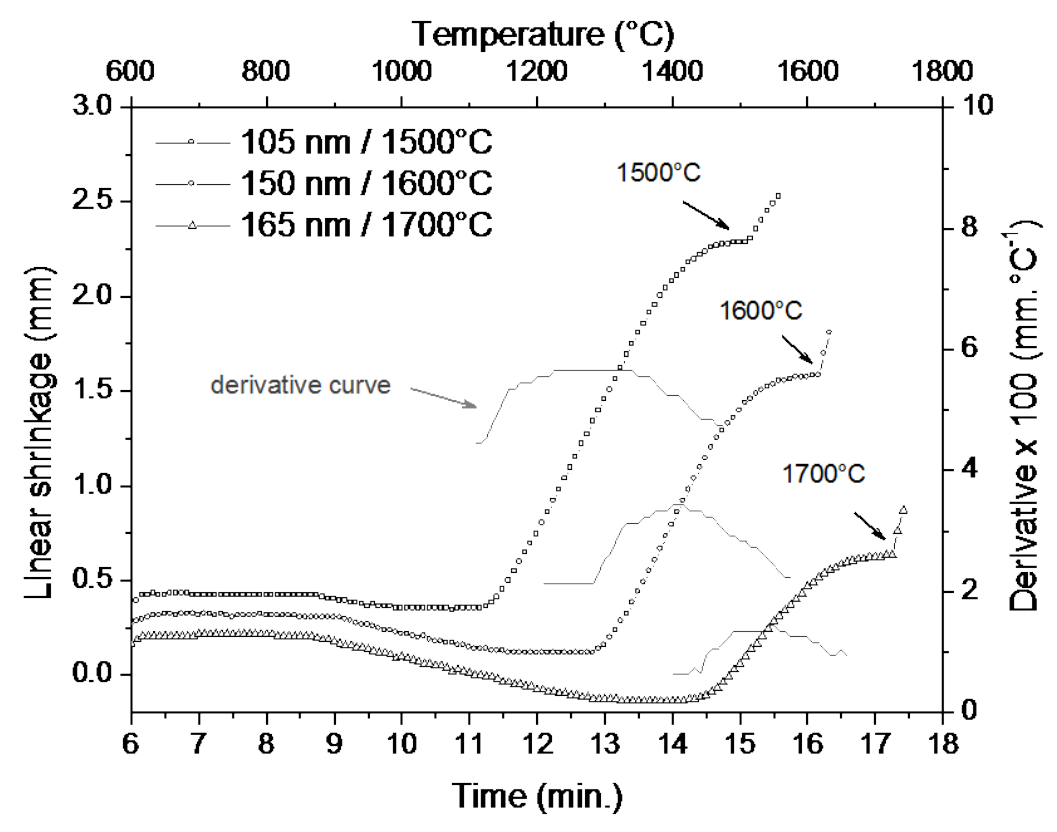

Figure 3. Linear shrinkage curves versus time / temperature for LSZO pellets at 100MPa and their derivative curves (grey lines).

After annealing at $800^{\circ} \mathrm{C}$ to remove the graphite foils, a pyrochlore phase without other parasitic phases was obtained for all the pellets. The particle sizes of these pellets were estimated from the width of the XRD lines. The software XND (18) enabled to determine both the crystallite size and the strain using the Hall-Williamson formula:

$$
\beta \cos \theta=\frac{K \lambda}{D}+4 \varepsilon \tan \theta
$$

where $\beta$ is the full peak width at half maximum, $\mathrm{K}$ is a constant taken as 0.9 that depends upon the particle shape and the Miller-indexes (hkl), $\theta$ is the Bragg angle, $\lambda$ is the wavelength of the radiation, $\mathrm{D}$ is the average particle size, and $\varepsilon$ is the mean strain. The crystallite size of the LSZO nanoparticles obtained from Equation 1 are reported in Table I. Surprisingly the strain decreased while the crystallite size increased with the sintering temperature. Obviously, the fine size of the powder helps reduce the sintering temperature required to reach the full density.

\section{Electrochemical Characterizations}

Incorporation of Protons. Since the discovery of high temperature protonic conductivity in cerates $(4,22)$, many investigations about perovskite-type proton conductors have been performed (23-25). These proton conductive perovskite- type oxides exhibit protonic conduction under hydrogen containing atmosphere at elevated temperatures. Generally, oxide ion vacancies $\left(V_{o}\right)$ are responsible for proton conduction at high temperatures under $\mathrm{H}_{2} \mathrm{O}$ containing atmosphere. To successfully incorporate protons in a material, oxygen vacancies are needed. Here strontium has been chosen as dopant for lanthanum zirconate pyrochlore to create oxygen vacancies. The samples can then be exposed to water vapor at elevated temperatures. The water gas is taken up into the structure due to the dissociation of the water molecule into a hydroxyl group and a proton. The hydroxyl group fills an empty oxygen site and the proton forms a covalent bond with 
oxygen atom in the structure. This can be described by the Kröger-Vink notation as follows:

$$
H_{2} O(g)+O_{O}^{x}+V_{O}^{*} \rightleftarrows 2 O H_{O}
$$

Electrical Properties. Electrochemical impedance spectroscopy (EIS) was used to evaluate the electrical conductivity of LSZO electrolyte in the $400^{\circ}-600^{\circ} \mathrm{C}$ temperature range in dry and wet $\left(5 \% \mathrm{H}_{2} \mathrm{O}\right)$ atmospheres. Figure $4 \mathrm{a}$ shows the typical AC impedance for the wet atmosphere, the same tendency was observed for the dry atmosphere. As expected, it was observed that the total conductivity in wet atmosphere was higher than that under dry atmosphere. A large crystallite size enhanced ionic conduction in both atmosphere conditions. For all of the pellets, except the electrode polarization (at low frequency), the bulk and grain boundary contributions could not be clearly distinguished, and this fact was confirmed by the impedance Bode plots (26). The experimental points were fitted by a least squares procedure using an equivalent circuit composed of a serie of ( $\mathrm{R} \| \mathrm{CPE}$ ) in order to determine electrical parameters of the LSZO ceramics. R is a pure resistance and CPE is a Constant-Phase Element. The complex impedance of these contributions is given by Equation [3]

$$
Z_{R}=R \quad Z_{C P E}=\frac{1}{Y_{0}(j \omega)^{p}}
$$

where $\mathrm{Y}_{0}$ is the module of the CPE and $p$ a parameter taking account of the depression of the semi circle. For all pellets, two $(\mathrm{R} \| \mathrm{CPE})$ were required for the simulation of the Nyquist plots, except for LSZO-1700 where three components (R \| CPE) in series were necessary. As seen on Figure 4b, a CPE behavior was clearly identified at high frequency. The CPE exponent $p$ was determined from the measured impedance spectra by the complex nonlinear least squares fitting method. Values were in the range 0.9-1.0 for all pellets under dry and wet atmospheres, $p=1.0$ representing a perfect capacitor (27). However when $p$ is close to 1.0, the CPE seems to be a capacitor, but the phase angle is not $90^{\circ}$. In this case of the LSZO-1700 sample, the semicircle was effectively depressed by an angle of $5^{\circ}$. One physical explanation for the CPE behavior could be the inhomogeneity and geometrical non-uniformity, which cause a frequency dispersion (28).
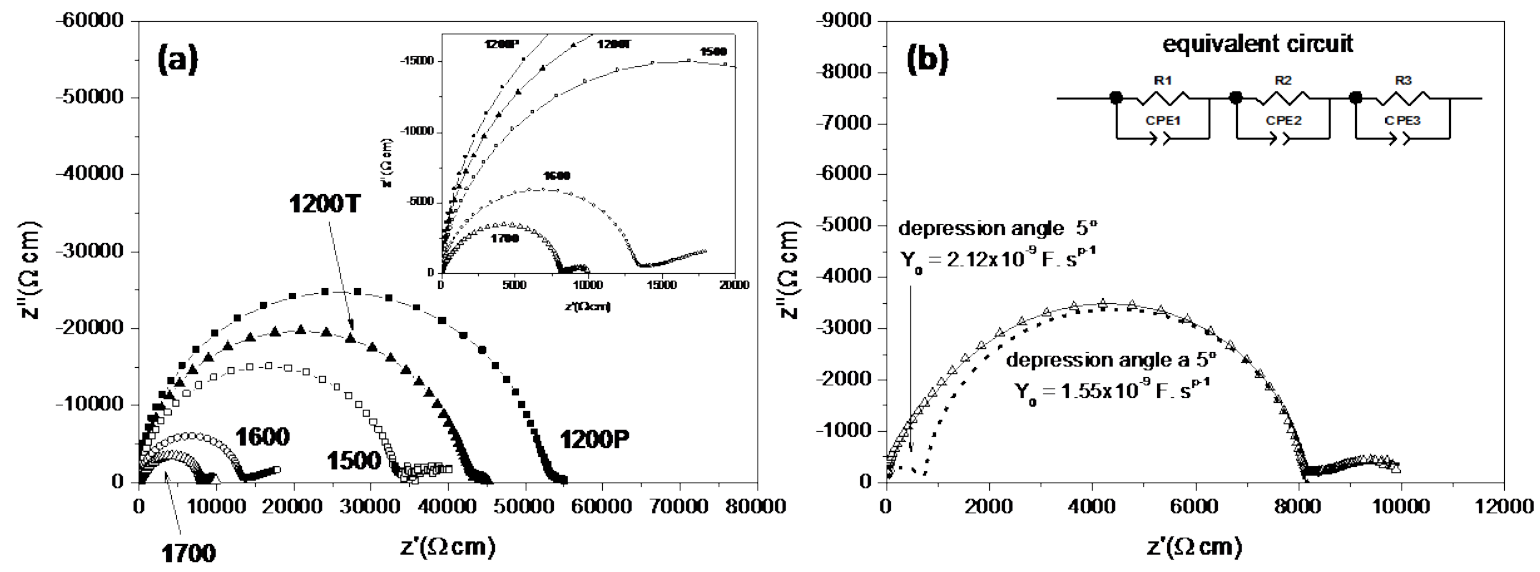

Figure 4. Nyquist plots of impedance spectra for LSZO pellets under wet atmosphere at $600^{\circ} \mathrm{C}$ (a) for all pellets (b) Simulation of the AC impedance spectrum of LSZO sintered at $1700^{\circ} \mathrm{C}$ with an equivalent circuit composed of three series of ( $\left.\mathrm{R} \| \mathrm{CPE}\right)$. 
The total electrical conductivity of dense pellets was presented in Figure 5 in an Arrhenius plot. An increase in the electrical conductivity in wet atmosphere (below $600^{\circ} \mathrm{C}$ ) was mainly because of proton conduction $(29,30)$. Indeed, the main charge carriers were protons in wet $5 \%$ atmosphere while the p-type conduction is dominant for dry atmosphere. The activation energies for proton transport were determined from the Arrhenius plots for pellets in dry and wet atmospheres and were reported in Table II. Except for the LSZO-1500 pellet, the activation energies were slightly higher in dry atmosphere than in wet atmosphere. For the full densified pellets, the ionic conductivities

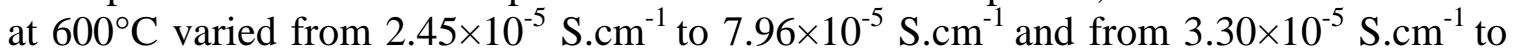
$1.19 \times 10^{-4}{\mathrm{~S} . \mathrm{cm}^{-1}}^{\mathrm{u}}$ under dry and wet atmospheres, respectively.

In order to explain the origin of grain boundary contribution in LSZO-1700 sample, its impedance behavior was compared with the LSZO-1200P under applied DC bias. The grain boundary resistance in LSZO-1700 was decreased with increasing the applied DC bias from $0 \mathrm{~V}$ to $1 \mathrm{~V}$, while the impedance behavior of LSZO-1200P remained unchanged. The dependence of grain boundary resistance and capacitance on DC bias is a powerful proof of the existence of space charge depletion at grain boundary (31). When $U_{D C}$ increased, the relative depletion of the mobile charge carriers (oxygen vacancies) decreased, leading to a decreased grain boundary resistance.
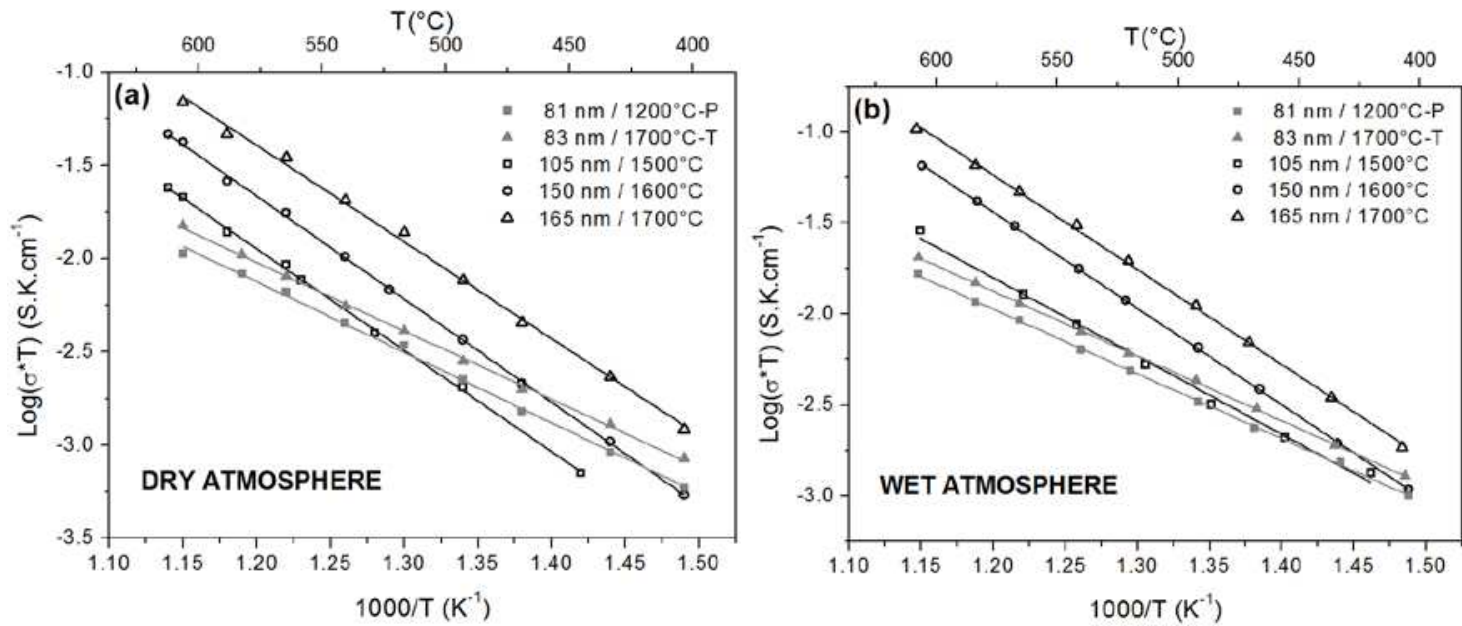

Figure 5. Total electrical conductivity of dense pellets in dry and wet atmospheres.

TABLE II. Activation energies calculated from the Arrhenius plots for pellets in different atmosphere.

\begin{tabular}{ccc}
\hline Name with the sintering temperature $\left({ }^{\circ} \mathbf{C}\right)$ & Ea $(\mathbf{e V}) /$ dry & Ea $(\mathbf{e V}) /$ wet \\
\hline LSZO-1200P & $0.75(1)$ & $0.70(1)$ \\
LSZO-1200T & $0.73(1)$ & $0.70(1)$ \\
LSZO-1500 & $1.08(1)$ & $0.85(2)$ \\
LSZO-1600 & $1.10(1)$ & $1.05(1)$ \\
LSZO-1700 & $1.03(2)$ & $1.03(1)$ \\
\hline
\end{tabular}

\section{Conclusion}

In summary, we have synthetized Sr-doped lanthanum zirconate pyrochlores $\mathrm{La}_{1.95} \mathrm{Sr}_{0.05} \mathrm{Zr}_{2} \mathrm{O}_{7-\delta}$ (LSZO) using a wet chemical route. A full densification was obtained only using a single step spark plasma sintering. Several sintering conditions were employed to obtain pellets with different particle size and relative densities. The 
electrochemical impedance measurements recorded under dry and wet atmosphere showed an enhancement of ionic conductivity under wet atmosphere.

\section{Acknowledgments}

The authors acknowledge close collaboration and discussions with B. Villeroy (Institut de Chimie et des Matériaux Paris Est, 94320 Thiais, France) for the SPS experiments.

\section{References}

1. S. C. Singhal, Solid State Ion., 135, 305-313 (2000).

2. C. Xia, W. Rauch, F. Chen, and M. Liu, Solid State Ion., 149, 11-19 (2002).

3. F. Chen, O. T. Sørensen, G. Meng, and D. Peng, J. Mater. Chem., 7, 481-485 (1997).

4. H. Iwahara, H. Uchida, K. Ono, and K. Ogaki, J. Electrochem. Soc., 135, 529533.

5. J.-C. Boivin, Int. J. Inorg. Mater., 3, 1261-1266 (2001).

6. F. M. B. Marques et al., Solid State Ion., 177, 1697-1703 (2006).

7. K. Huang and J. B. Goodenough, J. Alloys Compd., 303-304, 454-464 (2000).

8. B. C. H. Steele, Solid State Ion., 129, 95-110 (2000).

9. K. E. J. Eurenius, E. Ahlberg, and C. S. Knee, Dalton Trans., 40, 3946 (2011).

10. T. Shimura, M. Komori, and H. Iwahara, Solid State Ion., 86-88, Part 1, 685-689.

11. G. Kim et al., Int. J. Hydrog. Energy, 38, 1571-1587 (2013).

12. D. Marrero-López, L. dos Santos-Gómez, L. León-Reina, J. Canales-Vázquez, and E. R. Losilla, J. Power Sources, 245, 107-118 (2014).

13. F. Zhao and A. V. Virkar, J. Power Sources, 195, 6268-6279 (2010).

14. D. Wiedenmann et al., AIChE J., 59, 1446-1457 (2013).

15. C. Kjølseth et al., Solid State Ion., 181, 268-275 (2010).

16. A. Rizea, J. M. Raulot, C. Petot, G. Petot-Ervas, and G. Baldinozzi, Solid State Phenom., 106, 83-86 (2005).

17. D. Huo et al., Solid State Ion. (submitted).

18. J.-F. Berar and G. Baldinozzi, IUCr-CPD Newsl., 3-5 (1998).

19. R. D. Shannon, Acta Crystallogr. Sect. A, 32, 751-767 (1976).

20. S. Surblé et al., Phys. Chem. Miner., 37, 761-767 (2010).

21. T. Omata, K. Ikeda, R. Tokashiki, and S. Otsuka-Yao-Matsuo, Solid State Ion., 167, 389-397 (2004).

22. H. Iwahara, T. Esaka, H. Uchida, and N. Maeda, Solid State Ion., 3-4, 359-(1981).

23. O. Lacroix et al., J. Power Sources, 270, 506-515 (2014).

24. K. Yang et al., Ceram. Int., 40, 15073-15081 (2014).

25. H. Iwahara, H. Uchida, and S. Tanaka, Solid State Ion., 9-10, 1021-5 (1983).

26. J.-H. Hwang, D. S. McLachlan, and T. O. Mason, J. Electroceramics, 3, 7-16 (1999).

27. J. Bisquert, G. Garcia-Belmonte, P. Bueno, E. Longo, and L. O. S. Bulhões, J. Electroanal. Chem., 452, 229-234 (1998).

28. M. E. Orazem et al., J. Electrochem. Soc., 160, C215-C225 (2013).

29. D. Pergolesi et al., Nat. Mater., 9, 846-852 (2010).

30. Z. Sherafat et al., Electrochimica Acta, 165, 443-449 (2015).

31. M. Shirpour, R. Merkle, C. T. Lin, and J. Maier, Phys. Chem. Chem. Phys., 14, 730-740 (2011). 